\title{
Optimization of Operational and Constitutional Geometric Parameters for Thermoaoustic Energy Output
}

 \\ (Submit date : 2013. 10. 26., Judgment date : 2013. 11. 05., Publication decide date : 2014. 1. 4.)
}

\begin{abstract}
The effects of geometric parameters (stack position, stack length, resonator tube length) and varying input power over acoustic energy output were investigated. The acoustic laser kit (Garret 2000) was used for the construction of TA lasers. A series of sound pressure level measurements in different orientations did not differ significantly confirming that the sound wave generated could be assumed as a spherical wave. An increase in acoustic pressure was recorded with respective increase in input power, stack and resonator tube lengths owing to their relative influence over heat transfer rate and critical temperature gradient across the stack.
\end{abstract}

Key Words : Thermoacoustic laser, Sound pressure level(SPL), Frequency, Temperature gradient, Stack

\section{Introduction}

Thermo acoustic lasers convert heat from a high temperature heat source into acoustic power while rejecting waste heat to a low temperature sink. The working fluids involved can be air or noble gases which are non-toxic and environmentally benign. Simple in construction due to absence of moving parts, thermo acoustic lasers can be employed to achieve generation of electricity at individual homes, water-heating for domestic purposes, and to facilitate space heating and cooling. The possibility of utilizing waste heat or solar energy to run thermoacoustic devices makes them technically promising and economically viable to generate large quantities of acoustic energy.

Thermo acoustic phenomenon was first

$* * * * \dagger$ Wongee Chun(corresponding author) : Department of Nuclear \& Energy Engineering, Jeju National University.

**Sang Wonng Shin : Department of Nuclear \& Energy Engineering, E-mail : wgchun@jejunu.ac.kr, Tel : 064-754-3646 Jeju National University.

*Seung Jin Oh : Department of Nuclear \& Energy Engineering, Jeju National University.

***Kuan Chen : Department of Mechanical Engineering, University of Utah 
observed by European glassblowers over 200 years ago. Glassblowers heard sound when a cold glass tube was placed next to a hot glass stem. Glass tubes exhibiting such phenomenon with one end closed were named Sondhauss tubes after the scientist Sondhauss who studied these effects for the first time. Lord Rayleigh [1] qualitatively analyzed the thermo acoustic effect in his book, The Theory of Sound. About 150 years later, Rott [2] did an accurate quantitative discussion on the thermo acoustic effect. Feldman [3] commented that the most important milestone in experimental thermo acoustics came in 1962 when Carter suggested that the efficiency of Sondhauss tubes can be improved by introducing a solid structure, a stack, inside the resonator. G. W. Swift [4] has discussed the fundamentals of thermo acoustic engines in detail, by analysis and by discussing examples of thermo acoustic convertors. Swift illustrated the basic principles of thermo acoustic engines by considering an example of a single small solid plate aligned parallel to the direction of vibration of an acoustic plane standing wave. The author pointed out that with the introduction of a solid plate in a standing wave, the standing wave was modified resulting in two very important effects: (1) A time averaged heat flux near the surface the plate, along the direction of acoustic vibration, and (2) the generation or absorption of real acoustic power work near the surface of the plate. The author made numerous simple assumptions to derive these two basic effects for the case of a single plate introduced in a standing wave. Later in that paper, derivations were made for more complicated real life situations. Expressions for the critical temperature gradient, total heat flux along the stack, and total acoustic power produced derived by the author prove that the introduction of a solid stationary body in a standing wave stimulates the heat flux along the stack. The heat flux is about a thermal penetration depth from the solid boundary and the production or absorption of acoustic power by the fluid near the solid boundary.

The stack is one of the most important components of thermo acoustic devices. One of the problems faced by researchers in the past was the inability to explore the effects of various geometric factors of the stack including length, spacing, and general geometry. This was due to the difficulty involved with making stacks by hand. In a recent study, Ryan Lampe [5] used Selective Laser Sintering to produce a gamut of stack arrays such as square tubes, parallel plates, and a pin array. These fabricated stacks were then tested and their performances were compared using a compressor driven closed tube heat pump. It was observed that the drop of 4.3 $\mathrm{C}^{\circ}$ can be obtained across a parallel plate stack using a $12 \mathrm{~W}$ amplifier, with $130 \mathrm{mV}$ peak-to-peak of the sine-wave audio signal. Using the fabrication techniques discussed by the author, stack designs with $0.5 \mathrm{~mm}$ spacing could be manufactured. This work opened gates for better understanding of stack design on efficiency of thermo acoustic devices. Yong Tae Kim and Min 
Gon Kim [6] studied stack position dependency of a thermoacoustic prime mover based on the temperature difference across the stack. The authors measured acoustically produced temperature difference across the stack as the function of stack position and sound frequency. The measured positional variation of $\Delta \mathrm{T}$ across the stack matched empirical relations derived by Wheatley [7] and $\mathrm{CO}^{-}$workers when the stack length $\Delta \mathrm{x}$, was replaced by a fractional quantity $a \Delta x$. This is because the actual temperature distribution across the stack is skewed (S-shaped) with constant temperature plateaus at both ends.

Placement of the stack within the resonator is also important in terms of efficiency. The rate of heat transfer is directly proportional to acoustical velocity. Applying the principle of superposition, Fahey [8] suggested placing the maximum heat gradient at the point of maximum gas molecule velocity. In thermo acoustic devices, the maximum gas molecule velocity appears at approximately one third of the tube length from the closed end. The stack forms a heart of a thermo acoustic heat pump and recent researchers have focused more on stack geometry to improve the performance of thermo acoustic devices. Tijani, Zeegers and Waele [9] reported quantitative experimental investigation of the effect of pore dimensions on the performance of thermo acoustic devices and it was reported that the sheet spacing in stack of $2.58 \mathrm{k}$ should be optimum for cooling power. Given the mechanical simplicity of thermo acoustic devices, Garrett and Backhaus [10] predicted that these devices could be used to generate electricity at individual homes, to heat water for domestic purposes, and to produce space heating and cooling. Thermo acoustic refrigerators have already been employed on the space shuttle and aboard a Navy warship. Acoustic energy generated by thermo acoustic prime movers could be used for a variety of other applications. Ultrasounds are used in medical fields to break kidney stones or for treating tumors. Acoustic energy is also used for sanitizing liquids and for cleaning and sterilizing surfaces and medical instruments. Recent developments in thermo acoustics and the possibility of utilizing waste heat or solar energy for running thermo acoustic devices make it technically promising and economically viable to generate large quantities of acoustic energy.

Despite the aforementioned work, studies that have attempted to understand the effects of geometric parameters of thermo acoustic prime mover on acoustic output are scant. Accordingly, the primary aim of this research was to generate large quantities of high amplitude sound waves, by varying different geometric parameters including the stack length, the stack position, and the length of resonator.

\section{Experimental Arrangements and Procedures}

The Acoustic laser kit (Garrett 2000) provided by the Penn State Graduate Program in Acoustics was used for all experimental purposes. The kit consists of a Pyrex test tube as a resonator, a Celcor ceramic catalytic converter as a stack material, and 26 gauge nichrome $(\mathrm{NiCr})$ resistance heater wire. A 24 gauge copper magnet wire with enamel 
insulation was used for making necessary electrical connections. The stack was heated with the help of a nichrome $(\mathrm{NiCr})$ wire wound on one side of the stack and the other part was cooled by radiation and natural convection to the atmospheric air. The stack was made from a rectangular Celcor ceramic catalytic converter. Ideally, the cross section of the stack should be circular but an approximate octagonal shape with smoothened edges was carved out of the original converter. The original ceramic catalytic converter and the stack made from it are shown in Fig. 1

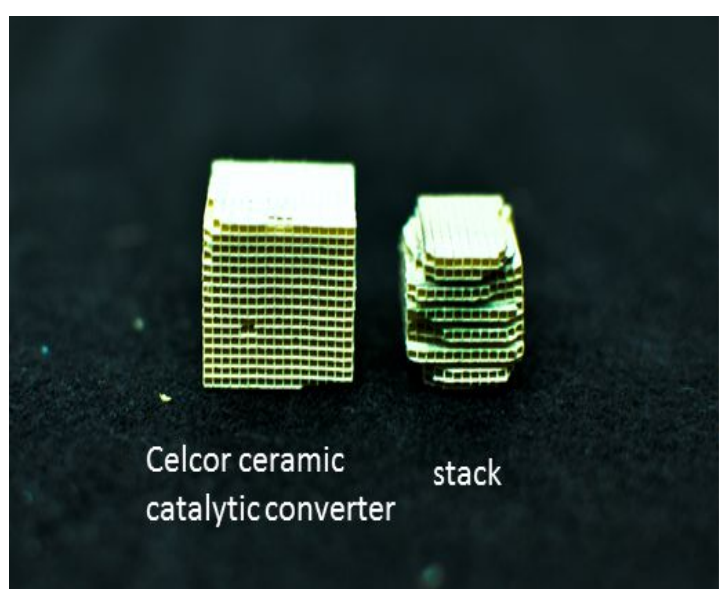

Figure 1. Original Celcor ceramic catalytic converter and the stack.

Six grooves about $3 \mathrm{~mm}$ deep were made on the top surface of the stack with the help of hacksaw and sandpaper. These grooves contained the serpentine nichore $(\mathrm{NiCr})$ heater wire. Two copper wires of length $60 \mathrm{~cm}$ were stripped by burning the enamel coating and were inserted through one of the channels of the ceramic stack. The exposed part of the copper wire was then twisted with the nichrome $(\mathrm{NiCr})$ wire to make a good electrical contact. This assembly was then inserted into the glass tube. The copper wires were fixed on the outer surface of the tube with the help of tape to prevent the stack from moving within the tube in axial direction. The stack with the heater wire wound on its side is shown in Fig. 2

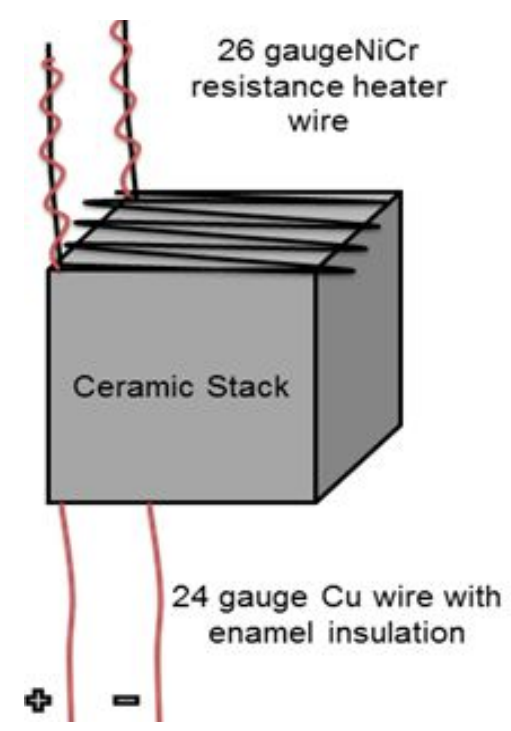

Figure 2. Stack and the heater wire assembly.

Three different lengths of resonators were tested, including $10 \mathrm{~cm}, 15 \mathrm{~cm}$ and $20 \mathrm{~cm}$. These resonators were also tested for different lengths of stack materials within the resonator. Stack positions were also varied within the resonator to observe optimum position for producing maximum acoustic power output. Different experimental conditions considered to find the optimum operating conditions of a thermo acoustic laser are listed in Table 1. 
Table 1. Different conditions for conducting experiments.

\begin{tabular}{|c|c|c|c|c|c|}
\hline $\begin{array}{l}\text { Cond- } \\
\text { itions }\end{array}$ & $\begin{array}{c}\mathrm{d} \\
(\mathrm{cm})\end{array}$ & $\begin{array}{c}\mathrm{Ls} \\
(\mathrm{cm})\end{array}$ & $\begin{array}{c}\mathrm{L}_{\mathrm{R}} \\
(\mathrm{cm})\end{array}$ & $\begin{array}{c}\text { Input } \\
\text { voltage }\end{array}$ & $\begin{array}{l}\text { Length of } \\
\text { Heater } \\
\text { wire }(\mathrm{cm})\end{array}$ \\
\hline Case I & $\begin{array}{l}2,4, \\
6,8 . .\end{array}$ & $\begin{array}{l}1.5, \\
2.5\end{array}$ & $\begin{array}{l}15, \\
20\end{array}$ & $\begin{array}{l}5.5 \mathrm{~V}, \\
6.5 \mathrm{~V}\end{array}$ & 13.5 \\
\hline $\begin{array}{c}\text { Case } \\
\text { II }\end{array}$ & $\mathrm{L} / 4$ & $\begin{array}{c}1.5, \\
2.5, \\
5\end{array}$ & $\begin{array}{l}15, \\
20\end{array}$ & $\begin{array}{l}5.5 \mathrm{~V}, \\
6.5 \mathrm{~V}\end{array}$ & 15.5 \\
\hline $\begin{array}{c}\text { Case } \\
\text { III }\end{array}$ & $\mathrm{L} / 4$ & 2.5 & $\begin{array}{l}15, \\
20\end{array}$ & $\begin{array}{l}5.5 \mathrm{~V}, \\
6.5 \mathrm{~V}\end{array}$ & 15.5 \\
\hline $\begin{array}{c}\text { Case } \\
\text { IV }\end{array}$ & $\mathrm{L} / 2$ & $\begin{array}{c}1, \\
1.25\end{array}$ & $\begin{array}{c}2.5,5, \\
7.5, \\
10 \\
20 \\
\end{array}$ & $\begin{array}{c}6 \mathrm{~V}, \\
6.5 \mathrm{~V}\end{array}$ & 15.5 \\
\hline
\end{tabular}

Where $\mathrm{d}$ is the distance of the stack measured from the open end of the tube, LS is the length of the stack material and LR is the length of the resonator.

A CEN-TECH 98025 multimeter was used to measure the voltage across the Nichrome $(\mathrm{NiCr})$ wire and connecting copper wires. A Tenma 72-942 sound level meter was used to measure sound pressure level of thermo acoustic laser at a distance of $10 \mathrm{~cm}$ away from the tube opening to avoid any disturbance due to sound level meter blocking and by aligning the microphone with the axis of the resonator tube. A National Instruments data acquisition (DAQ) device, NI USB 6009 in conjunction with unidirectional microphone was used to acquire the frequency signal. Lab VIEW Signal Express was used for analyzing the data acquired using the DAQ device. Signal Express can acquire, generate, analyze, compare, import and log signals. Multiple sets of experiments were conducted to check acoustic output of a thermo acoustic laser by varying stack position, stack length, input power and length of a resonator.

Three different stack lengths $(12.5 \mathrm{~mm}$, $25 \mathrm{~mm}$ and $50 \mathrm{~mm}$ ) were tried to check the effects of stack length on the performance of a thermo acoustic laser.

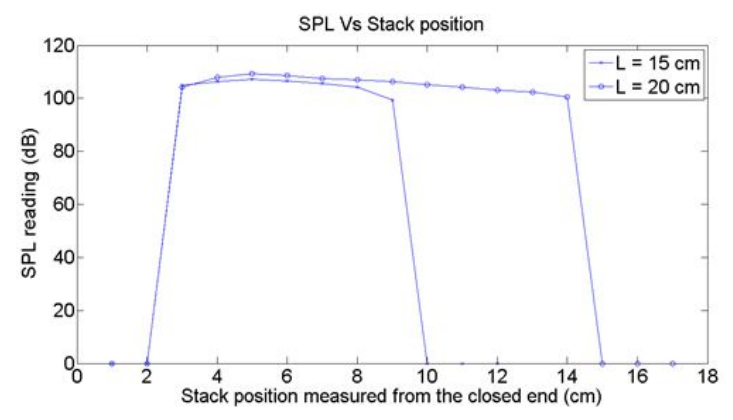

Figure 3. SPL vs Stack position for $L=15 \mathrm{~cm} \& 20 \mathrm{~cm}$, stack length $=1.25 \mathrm{~cm}$.

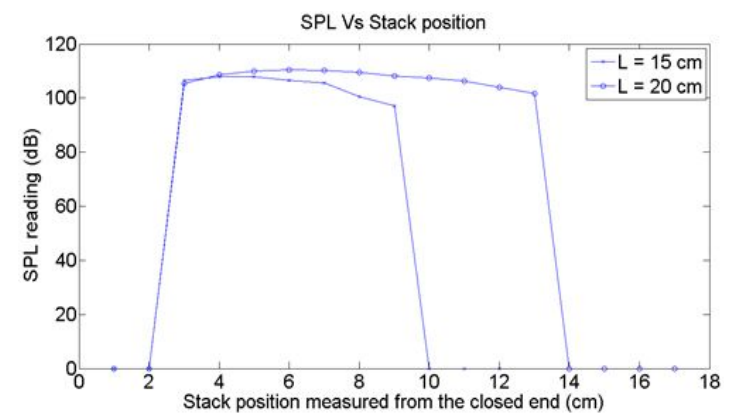

Figure 4. SPL vs Stack position for $\mathrm{L}=15 \mathrm{~cm} \& 20 \mathrm{~cm}$, stack length $=2.5 \mathrm{~cm}$.

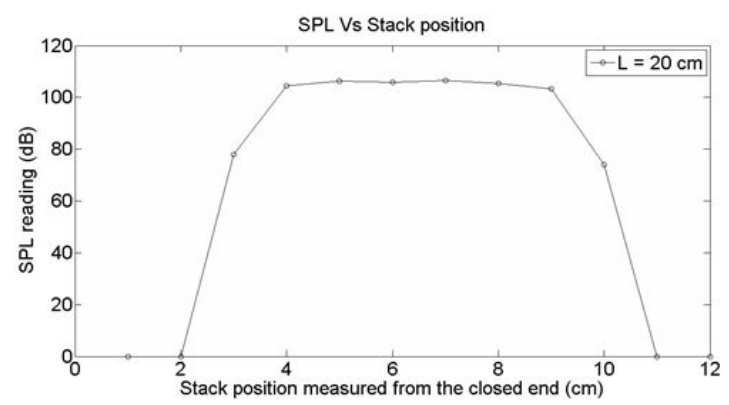

Figure 5. SPL vs Stack position for $L=20 \mathrm{~cm}$, stack length $=5 \mathrm{~cm}$. 
$12.5 \mathrm{~mm}$ stack was made by cutting the $25 \mathrm{~mm}$ stack with the help of a hacksaw. 50 $\mathrm{mm}$ stack was made by placing two stacks of $25 \mathrm{~mm}$ length close to each other such that the pores of both the stack materials are perfectly aligned. More observations were made by changing the input voltage values for the thermo acoustic laser. Sometimes, the wires shorted out broke at the junction of copper wire and $\mathrm{NiCr}$ wire due to contact resistance. The wires were replaced with the exact lengths of the same materials whenever it was necessary to maintain consistency in the results.

\section{Results and Discussion}

Sound pressure level (SPL) measurements were taken by arranging the SPL meter in three different orientations $\left(0^{\circ}, 45^{\circ}\right.$ and $\left.90^{\circ}\right)$. SPL measurements were also taken by varying the distance of the SPL sensor from the tube opening in these directions. Data was recorded for two different input voltage values and the results were consistent in both cases.

Sound pressure levels decreased rapidly with distance after exiting the tube opening and remained almost the same even at a great distance from the tube opening. SPL readings in different directions differed only slightly. The assumption of spherically spreading wave is thus valid. Slight increase in sound pressure level was observed at a distance of about $1 / 2$ wavelength position from the tube opening. Theoretically, air displacement amplitude is highest at this position in a plane standing wave. The SPL meter recorded the highest sound pressure levels at the tube opening, which is a pressure node. In a standing wave, pressure (static) oscillations are zero at the tube opening and flow velocity oscillations are the highest. Oscillations in dynamic pressure are due to the deceleration of air flow when the flow impacts the SPL meter surface. The SPL meter measured the intensity of the total (static plus dynamic) pressure fluctuations. As the distance from the tube opening increased, the SPL readings decreased and at a distance of $\frac{1}{2}$ wavelengths from the tube opening the SPL reading slightly increased. The dynamic pressure oscillations contributed more to the SPL readings than the static pressure oscillations.

A $15 \mathrm{~cm}$ long quarter wavelength thermo acoustic laser and a $20 \mathrm{~cm}$ long quarter wavelength thermo acoustic laser were tested to check the optimum position of the stack within the resonator. The position of the stack was measured from the closed end of the resonator. Three different stacks with thicknesses of $12.5 \mathrm{~mm}, 25 \mathrm{~mm}$ and $50 \mathrm{~mm}$ were used in the experiments. The results were consistent in all the cases with optimum stack position being approximately 1/4th of the tube length from the closed end of the resonator. According to Kwon [11], the theoretical optimum position of a stack is near the midpoint of a prime mover. Experimental investigation by Kwon [11] revealed that the maximum output is between a third and a half of the length of the prime mover from 
the closed end. The author points out that this shift in the position of maximum output towards the closed end is due to the interaction of the resonator with the outside air at the open end. Experimental data collected in current investigation suggests that, even though the maximum output is at a quarter of the length of the prime mover from the closed end, the output remains fairly constant between a quarter and a half of the length of the prime mover from the closed end.

Table 2. Sound pressure level measurements for different stack lengths.

\begin{tabular}{|c|c|c|c|c|}
\hline $\begin{array}{l}\text { Experimental } \\
\text { set up }\end{array}$ & $\begin{array}{l}\text { SPL }(\mathrm{dB}) \\
\text { (Max) for } \\
\text { stack } \\
\text { length } \\
=1.25 \mathrm{~cm}\end{array}$ & $\begin{array}{l}\text { SPL(dB) } \\
(\mathrm{Avg}) \text { for } \\
\text { stack } \\
\text { length } \\
=1.25 \mathrm{~cm}\end{array}$ & $\begin{array}{l}\text { SPL(dB) } \\
\text { (Max) for } \\
\text { stack } \\
\text { length } \\
=2.5 \mathrm{~cm}\end{array}$ & $\begin{array}{c}\text { SPL(dB) } \\
\text { (Avg) for } \\
\text { stack } \\
\text { length } \\
=2.5 \mathrm{~cm}\end{array}$ \\
\hline $\begin{array}{c}\mathrm{L}=15 \mathrm{~cm} \\
\mathrm{Vin}=6.28 \mathrm{~V} \\
\mathrm{r}=10 \mathrm{~cm}\end{array}$ & 109.5 & 107.5 & 109.5 & 108.6 \\
\hline $\begin{array}{c}\mathrm{L}=20 \mathrm{~cm}, \\
\mathrm{Vin}=6.35 \mathrm{v}, \\
\mathrm{r}=10 \mathrm{~cm}\end{array}$ & 107.5 & 105.2 & 109.3 & 108.5 \\
\hline
\end{tabular}

Three different stacks of lengths $12.5 \mathrm{~mm}$ $25 \mathrm{~mm}$ and $50 \mathrm{~mm}$ were tested. Spacing between the plates of the stack was not varied due to fabrication complications. However, recent study by Tijani [9] has shown that the optimum spacing between two stack plates for parallel plate stack should be 38k . The stack was positioned at L/4 distance from the closed end, which was observed to be the optimum stack position for producing maximum output in quarter wavelength prime movers. The maximum and average values of sound pressure levels increased with the stack length. The effect of stack length on acoustic output was observed in both $15 \mathrm{~cm}$ long and $20 \mathrm{~cm}$ long thermo acoustic lasers and the results are presented in Table 2.

The thermo acoustic power output is proportional to the volume of the fluid present within thermal penetration depth from the plate. As the stack length increases, this volume increases. The acoustic power is also proportional to the ratio of actual temperature gradient to critical temperature gradient. When the stack length is increased and the input power is kept the same, the temperature gradient decreases.

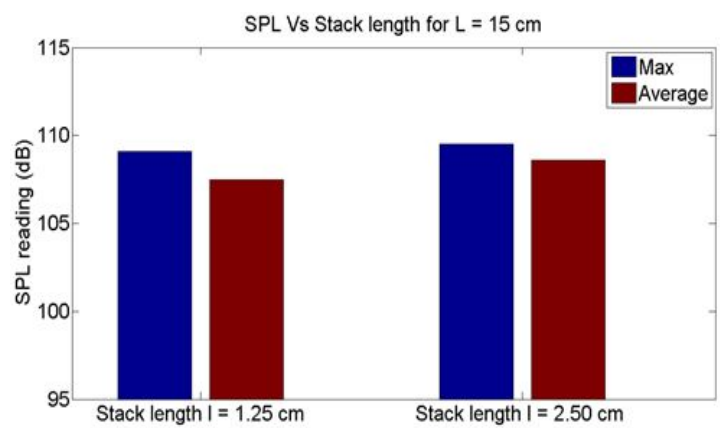

Figure 6. SPL (max and average) vs Stack Length for tube length $L=15 \mathrm{~cm}$.

Thus increasing the stack length creates two effects: 1) the volume of the fluid within thermal penetration depth from the plate surface increases, which increases the acoustic power output and 2) the temperature gradient across the stack length decreases, which decreases the acoustic power output. Under our experimental conditions, the net 
effect of increasing the stack length was an increase in the acoustic power output. The experimental results of sound pressure level variations with stack length for two different resonator tube lengths are shown in Fig. 6 and 7.



Fig. 7. SPL (max and average) vs Stack Length for tube length $L=20 \mathrm{~cm}$.

Sound pressure level measured for two different resonator tube lengths of $15 \mathrm{~cm}$ and $20 \mathrm{~cm}$ revealed that excessive surface area of longer resonator tube provides stack effect, which is responsible for higher sound pressure level output as depicted by Table 3 and Fig. 8.

Table 3. SPL for different tube lengths.

\begin{tabular}{ccccc}
\hline $\begin{array}{c}\text { stack } \\
\text { length }\end{array}$ & $\begin{array}{c}\text { SPL } \\
(\mathrm{dB})\end{array}$ & $\begin{array}{c}\text { SPL }(\mathrm{dB}) \\
\text { for }\end{array}$ & $\begin{array}{c}\text { Rise in } \\
\text { SPL }\end{array}$ & $\begin{array}{c}\text { Percent } \\
\text { age }\end{array}$ \\
$\begin{array}{c}\text { Vin }= \\
6.5 \mathrm{v}\end{array}$ & $\begin{array}{c}\text { cm, stack } \\
\text { position } \\
\text { at } 5 \mathrm{~cm}\end{array}$ & $\begin{array}{c}\text { L=20cm, } \\
\text { stack } \\
\text { position } \\
\text { at } 6 \mathrm{~cm}\end{array}$ & $\begin{array}{c}\text { reading } \\
(\mathrm{dB})\end{array}$ & $\begin{array}{c}\text { Rise } \\
(\%)\end{array}$ \\
\hline $\begin{array}{c}\text { Max } \\
\text { value }\end{array}$ & 109.2 & 110.1 & 0.9 & 0.824 \\
\hline $\begin{array}{c}\text { Avg. } \\
\text { value }\end{array}$ & 108.5 & 109.6 & 1.1 & 1.014 \\
\hline
\end{tabular}

Increasing the input voltage generated higher sound pressure levels. Higher input voltage generates a higher temperature gradient across the stack, which in turn produces higher acoustic power output as given by the Table 4 and Fig. 9

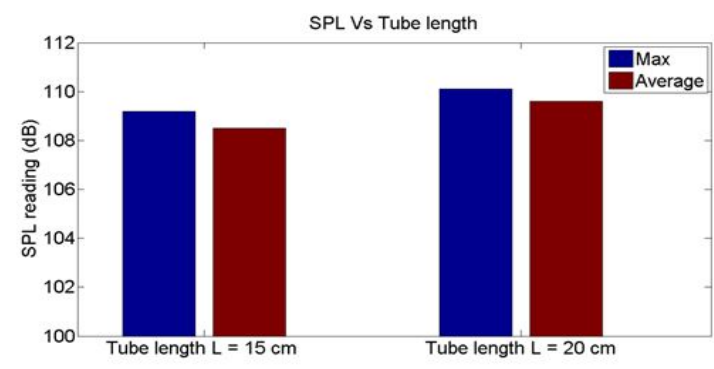

Figure 8. SPL (max and average) vs tube length for stack length $=2.5 \mathrm{~cm}$.

High frequency thermo acoustic lasers can be constructed by reducing the length of the resonator. The resonant frequency depends on the length of the prime mover.

Table 4. SPL for different input voltages at resonator length $=15 \mathrm{~cm}$.

\begin{tabular}{|c|c|c|c|c|}
\hline $\begin{array}{c}\text { stack } \\
\text { length } \\
=2.5 \mathrm{~cm} \text {, } \\
\text { stack } \\
\text { position } \\
\text { at } \\
5 \mathrm{~cm}\end{array}$ & $\begin{array}{c}\text { SPL } \\
(\mathrm{dB}) \text { for } \\
\text { Vin }= \\
6 \mathrm{~V}\end{array}$ & $\begin{array}{c}\text { SPL } \\
(\mathrm{dB}) \text { for } \\
\text { Vin = } \\
6.5 \mathrm{v}\end{array}$ & $\begin{array}{l}\text { Rise } \\
\text { in } \\
\text { SPL } \\
\text { (dB) }\end{array}$ & $\begin{array}{c}\text { Percent- } \\
\text { age } \\
\text { rise } \\
(\%)\end{array}$ \\
\hline $\begin{array}{c}\text { Max } \\
\text { value }\end{array}$ & 107.7 & 109.2 & 1.5 & 1.4 \\
\hline $\begin{array}{l}\text { Avg. } \\
\text { value }\end{array}$ & 106 & 108.4 & 2.4 & 2.26 \\
\hline
\end{tabular}

A $2.5 \mathrm{~cm}$ long stack was used in $15 \mathrm{~cm}$ and $20 \mathrm{~cm}$ prime movers and it was positioned at a distance of $\mathrm{L} / 4$ from the closed end of the resonator. SPL readings and microphone readings 
were taken at $10 \mathrm{~cm}$ from the open end. The USB 2009 data acquisition device and Signal Express was used to acquire and analyze the signal. The $10 \mathrm{~cm}$ long prime mover recorded the fundamental frequency of 885 and the $20 \mathrm{~cm}$ long recorded $437 \mathrm{~Hz}$, which were very close to the theoretical values (860 $\mathrm{Hz}$ and $430 \mathrm{~Hz}$ ). Fig. 10 and 11 define the measured frequency responses.

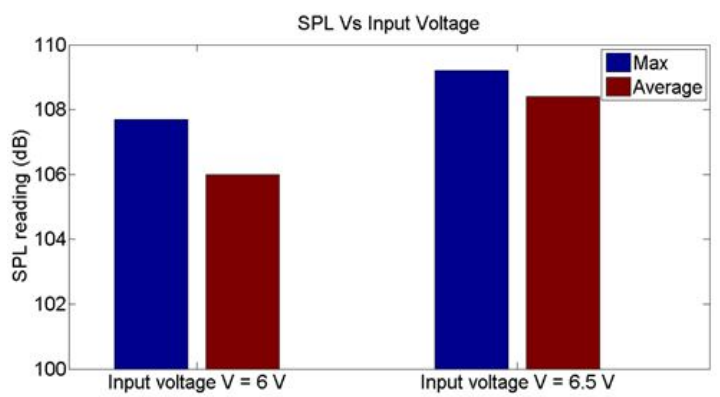

Fig. 9. SPL (max and average) vs Input Voltage.

Sound output power can be calculated by the Eq. (1)

$$
P_{\text {out }}=4 \pi r^{2} p_{r m s^{2}} /(\rho c)
$$

Where, $r$ is the distance from tube opening, Prms is the root mean square value of pressure fluctuations derived by SPL measured value, $\rho$ is density of the air and, $\mathrm{C}$ is the speed of sound. Garrett [12] suggested that the sound pressure measurement recorded at 1 meter from the tube opening provides a useful (not exact) measurement of the total radiated acoustic power. Experiments were conducted to measure the SPL readings at different distances from the tube opening along the axis of the tube and the corresponding sound power outputs were calculated using Eq.(1). The results are as shown in Table 5.

Table 5. Sound power calculated at different distances from the tube opening.

\begin{tabular}{lrcc}
\hline $\begin{array}{l}\text { Distance from the } \\
\text { tube opening }(\mathrm{m})\end{array}$ & $\begin{array}{c}\text { SPL } \\
(\mathrm{dB})\end{array}$ & $\begin{array}{c}\mathrm{P}_{\mathrm{rms}} \\
(\mathrm{Pa})\end{array}$ & $\begin{array}{c}\text { Power } \\
(\mathrm{mW})\end{array}$ \\
\hline 0.25 & 104.2 & 3.24 & 23.56 \\
\hline 0.5 & 97.4 & 1.48 & 19.69 \\
\hline 0.75 & 95.3 & 1.16 & 27.31 \\
\hline 1.0 & 90.8 & 0.69 & 17.23 \\
\hline 1.25 & 89.4 & 0.59 & 19.50 \\
\hline
\end{tabular}

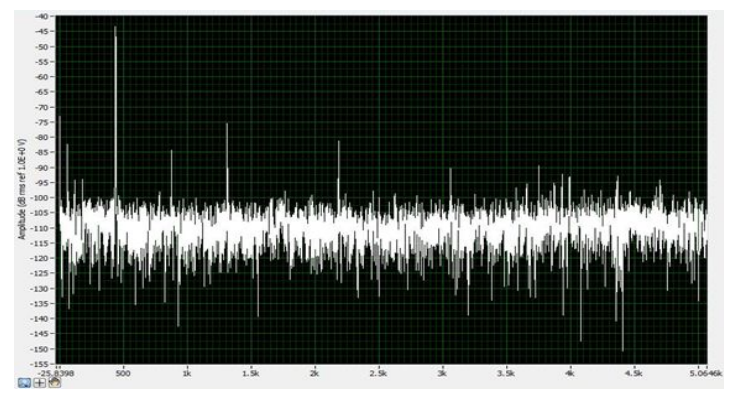

Fig. 10. Frequency chart for a $20 \mathrm{~cm}$ long thermo acoustic laser.

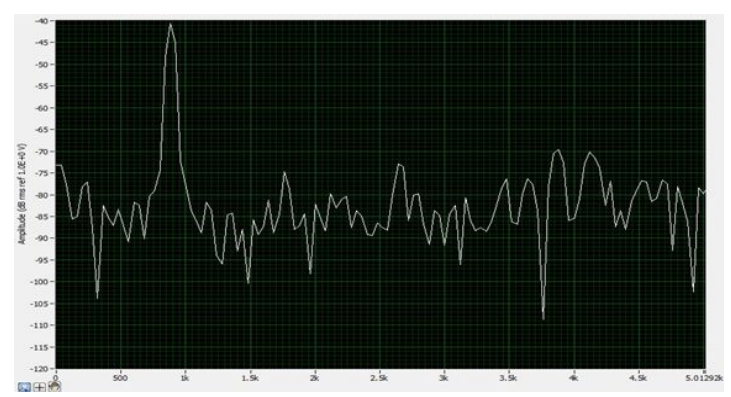

Fig. 11. Frequency chart for a $10 \mathrm{~cm}$ long thermo acoustic laser.

For different locations from the tube opening, the acoustic power output varied from 17.23 $\mathrm{mW}$ to $27.32 \mathrm{~mW}$. For a spherical wave, the acoustic power measured at any location 
from the point source should be the same. An uncertainty analysis [13] introduced in our previous research work [14] was performed to determine the reliability of experimental results. All the uncertainty estimates were based on 95 percent confidence levels. The uncertainty interval for voltage measured by the multimeter was $=0.25 \mathrm{~V}$ as specified by the manufacturer. The uncertainty interval of length measurements was assumed to be $0.002 \mathrm{~m}$, which gave the uncertainty interval for resistance measurements as $=0.002 \mathrm{x}$ $2.571 / 0.3=0.01714 \mathrm{Ohm}$. The uncertainty interval of the sound pressure level measurement was $1.5 \mathrm{~dB}$, as specified by the manufacturer. The uncertainty interval in Power was determined by Eq. (2) as

$$
\begin{aligned}
& \mathrm{WP}=[\{(\partial \mathrm{P} / \partial \mathrm{V}) \mathrm{x} W \mathrm{WV}\} 2+\{(\partial \mathrm{P} / \partial \mathrm{R}) \\
& \mathrm{x} \quad \mathrm{WR}\} 2] 1 / 2
\end{aligned}
$$

Using this equation, Power uncertainty varies from $11.451 \%$ to $8.229 \%$ for $\mathrm{P}=$ $18.942 \mathrm{~W}$ to $\mathrm{P}=37.437 \mathrm{~W}$.

\section{Conclusion}

The stack is one of the most important components of thermo acoustic devices. One of the problems faced by researchers in the past was the inability to explore the effects of various geometric factors of the stack including length, spacing, and general geometry. As the previous studies that have been attempted to understand the effects of geometric parameters of thermo acoustic prime mover on acoustic output were scant, the current experimentation results would provide an ample insight about the relative effects of different configurational parameters over the thermo acoustic output.

The investigation of various geometric parameters such as stack position, stack length and resonator tube length along with the variation in input voltage revealed that an increase in stack length, resonator tube length and input voltage promoted higher sound pressure levels. The SPL measurements in different orientations did not differ significantly which confirms that the sound wave generated could assumed to be a spherical wave. The maximum SPL value was measured with the stack positioned at a distance of $\mathrm{L} / 4$ lengths from the closed end of resonator. The maximum acoustic power recorded by acoustic lasers was $20.24 \mathrm{~mW}$ for $39 \mathrm{~W}$ of electric input.

\section{Acknowledgments}

This work was supported by the National Research Foundation of Korea(NRF) grant funded by the Ministry of Science, ICT \& Future Planning (No. 2009-0092786)

\section{REFERENCE}

1. Rayleigh. The explanation of certain acoustical phenomena. Nature 1878; 18: 319-21.

2. Rott, N. Thermo acoustics. Advances in Applied Mechanics 1980; 20: 135-75.

3. Feldman Jr, K.T., 1968. Review of the literature on Sondhauss thermo acoustic phenomena. J Sound and Vibration 1968; 7(1): 71-82. 
4. Swift, G. Thermo acoustic Engines. J Acoustical Society of America 1968; 84: 1145-80.

5. Lampe, R. Design and Testing of Rapid Prototyped Stacks for Thermo acoustic Applications. Proceedings of The National Conference on Undergraduate Research (NCUR) 2008:1-8.

6. Kim, Y.T. \& Kim, M.G., 2000. Optimum Positions of a Stack in a Thermo acoustic Heat Pump. J Korean Physical Society; 36(5): 279-86.

7. Wheatley, J., Hofler, T., Migliori, A. An intrinsically irreversible thermo acoustic heat engine. J. Acoust. Soc. Am1983; 74(1): 153-70.

8. Fahey, D., 1992. Thermo acoustic oscillations in cryogenics. Part 3: avoiding and damping of oscillations. Cryogenics1992; 32(8):703-06.

9. Tijani, M.E.H., Zeegers, J.C.H., de Waele, a. T. a. M., 2002. The optimal stack spacing for thermo acoustic refrigeration. J Acoustical Society of America2002; 112(1):128.

10. Garrett, S. L., \& Backhaus, S. The Power of Sound. Sigma Xi, The Scientific Research Society2000; 88(6):516-25.

11. Kwon, Y. S. Study of Thermo acoustic Engines Operating at Frequencies between $2 \mathrm{KHz}$ and $25 \mathrm{KHz}$. Ph.D. dissertations, Department of Physics, The University of Utah 1996.

12. Garrett, S. L. Acoustic laser kit instructions. Applied Research Laboratory, Penn State University, State College, PA 2005.

13. Kline, S. J., McClintock, F. A., 1953. Describing Uncertainties in Single-Sample Experiments, J. Mech. Eng2005; 75: 3-8.

14. Chen K, Oh SJ, Lee YJ, Chun W. Acoustic energy output and coupling effect of a pair of thermo acoustic lasers. Int. J. Energy Research 2011; 36(4):477-785. 